\title{
The Formazanate Ligand as Electron Reservoir: Bis(Formazanate) Zinc Complexes Isolated in Three Redox States
}

\author{
Mu-Chieh Chang, Thomas Dann, David P. Day, Martin Lutz, Gregory G. Wildgoose, and Edwin \\ Otten*
}

Metal-mediated redox processes are of fundamental importance in a wide variety of bond formation and cleavage reactions. The utility of transition metal catalysts in this type of reactions stems from their ability to switch between two (or more) oxidation states. Recently, there has been increased interest in redox processes that do not occur at the metal centre, but instead take place within the ancillary ligand framework (so-called 'redox-active' or 'non-innocent' ligands) ${ }^{[1]}$ The use of organic ligands as redox equivalents is of key importance in biological (enzymatic) transformations, ${ }^{[2]}$ and has been shown to open new reactivity pathways in catalysis. ${ }^{[1 c]}$ The most studied ligands of this class are dithiolenes and dioxolenes, while recent work has focussed on $\alpha$-diimines ${ }^{[3]}$ and bis(imino)pyridines. ${ }^{[4]}$

A class of ligands that has found widespread utility in the synthesis of metal complexes across the periodic table are the monoanionic $\beta$ diketiminates. ${ }^{[5]}$ These are generally considered as stable ligand scaffolds without involvement in redox-chemistry. Recently, examples of $\beta$-diketiminate metal complexes were reported in which the ligand was either reduced to a metal-bound di- or trianion, ${ }^{[6]}$ or oxidized to a neutral radical species. ${ }^{[7]}$ However, the limited stability of $\beta$-diketiminate complexes upon changing oxidation state prevents widespread application. ${ }^{[8]}$

Formazanates $(1,2,4,5$-tetraazapentadienyls $),{ }^{[9]}$ which are close analogues of $\beta$-diketiminates, have received comparatively little attention as ligands in coordination chemistry. ${ }^{[10]}$ The stability of organic 6-membered heterocyclic radicals (verdazyls) that are

[*] Mu-Chieh Chang, Dr. Edwin Otten

Stratingh Institute for Chemistry, University of Groningen Nijenborgh 4, 9747 AG Groningen, The Netherlands E-mail: edwin.otten@rug.nl

Dr. Martin Lutz

Bijvoet Center for Biomolecular Research, Crystal and Structural Chemistry, Utrecht University, Padualaan 8, 3584 $\mathrm{CH}$ Utrecht, The Netherlands

Thomas Dann, Dr David P. Day, Dr. Gregory G. Wildgoose Energy \& Materials Laboratory, School of Chemistry, University of East Anglia, Norwich Research Park, Norwich, NR4 7TJ, United Kingdom

[**] GGW and DPD thank the European Research Council for funding (ERC Grant Agreement n ${ }^{\circ}$ ERC-StG-307061 PiHOMER). GGW thanks the Royal Society for additional support via a University Research Fellowship. TD thanks the University of East Anglia for financial support via a Dean's studentship. NWO is gratefully acknowledged for funding (Veni grant to EO). We thank Prof. B. de Bruin (University of Amsterdam) for help with VT-EPR experiments and $A$. Meetsma for useful discussions on the X-ray crystallography.

Supporting information for this article is available on the WWW under http://www.angewandte.org or from the derived from formazans prompted us to explore the use of formazanates as potential redox-active ligands (Chart 1). Here we show that zinc complexes with formazanate ligands engage in remarkably facile and reversible redox-chemistry which allows the full characterization of bis(formazanate) $\mathrm{L}_{2} \mathrm{Zn}$ complexes in charge neutral, anionic or dianionic redox states.

\section{Chart 1}

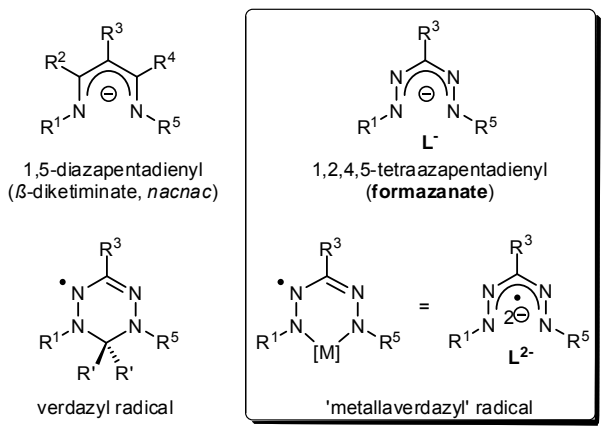

Bis(formazanate) zinc complexes are readily accessible by protonolysis of $\mathrm{Me}_{2} \mathrm{Zn}$ with the neutral ligand precursors $\mathrm{PhNNC}(p$ tol)NNHPh (1a) and $\mathrm{PhNNCH}\left({ }^{t} \mathrm{Bu}\right) \mathrm{NNPh}$ (1b). In the case of formazan 1a, an immediate colour change from red to intense blue is observed to indicate formation of the bis(formazanate) complex $\left(\mathrm{PhNNC}(p \text {-tol)NNPh })_{2} \mathrm{Zn}\right.$ (2a, Scheme 1). Yellow 1b also reacts immediately with $\mathrm{Me}_{2} \mathrm{Zn}$, but in this case heating to $50{ }^{\circ} \mathrm{C}$ overnight was required to obtain full conversion to $\left(\mathrm{PhNNC}\left({ }^{t} \mathrm{Bu}\right) \mathrm{NNPh}\right)_{2} \mathrm{Zn}$ (2b, Scheme 1). Both complexes are obtained in good yield (>75\%) by crystallization as intensely coloured solids. Single crystal x-ray diffraction studies (Figures 1 and S1, pertinent bond distances in Table 2 and S2) reveal a very similar tetrahedral geometry around the central $\mathrm{Zn}$ atom. ${ }^{[1]]}$ As is the case in related $\beta$-diketiminate complexes, full delocalization within the formazanates is indicated by the equivalent $\mathrm{N}-\mathrm{N}$ and $\mathrm{C}-\mathrm{N}$ bond lengths in the backbone of each ligand. ${ }^{[12]}$

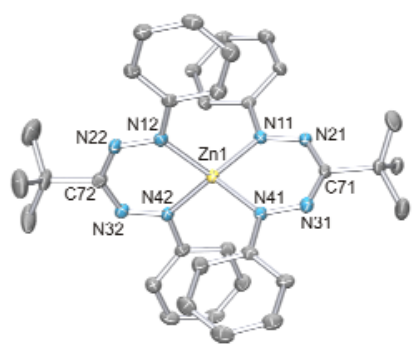

Figure 1. Molecular structure of $\mathbf{2 b}$ showing $50 \%$ probability ellipsoids. The hydrogen atoms are omitted for clarity. 
In order to establish the redox-active nature of the formazanate ligands in compounds 2 , we ran cyclic voltammetry experiments in THF solution with $\left[\mathrm{Bu}_{4} \mathrm{~N}\right]\left[\mathrm{B}\left(\mathrm{C}_{6} \mathrm{~F}_{5}\right)_{4}\right]$ electrolyte. ${ }^{[13]}$ Upon scanning in a reductive direction the $\mathrm{CV}$ shows two quasi-reversible, singleelectron redox processes, labelled system I/I' and II/II' (Figure 2). These correspond to the reversible formation of the radical anions of $\mathbf{2 a}$ and $\mathbf{2} \mathbf{b}\left(\mathbf{2} \mathbf{a}^{-}\right.$or $\mathbf{2} \mathbf{b}^{-}$; system I/I') and the corresponding dianions $\left(2 \mathbf{a}^{2-}\right.$ or $\mathbf{2} \mathbf{b}^{2-}$; system II/II') respectively. If the scan direction is reversed after the reductive peak I but before peak II, then the reoxidation of the radical anion (2a- or $\mathbf{2} \mathbf{b}^{-}$) is once again observed as peak I' indicating that each redox process is sequential and independent. When the scan rate is varied between 100 and 1000 $\mathrm{mVs}^{-1}$ all processes exhibited a linear relationship between peak current and the square root of the voltage scan rate, indicative of diffusion-controlled redox processes. Excellent fits between experiment and digital simulation of the cyclic voltammetry of 2a and $\mathbf{2 b}$ (Figure 2) yielded optimised values of formal potentials, $E^{0}$, and electron transfer rate constants, $k^{0}$ listed in Table 1. Replacing the inductively electron donating tert-butyl group with the electron withdrawing $p$-tolyl group on the formazanate ligands has the expected effect on the reduction potentials (Table 1). Interestingly, the one-electron reduction of both bis(formazanate)zinc complexes 2a and $\mathbf{2 b}$ occurs at more negative potentials $\left(E_{I / T}^{0}=-1.31 \mathrm{~V}\right.$ vs. $\mathrm{Fc}^{0 /+}, \mathbf{2 a} ;-1.57 \mathrm{~V}$ vs. $\left.\mathrm{Fc}^{0 /+}, 2 \mathbf{b}\right)$ than Hicks and co-workers have reported for boron mono(formazanate) compounds $\left(E^{0} \sim-0.9 \mathrm{~V}\right.$ vs. $\left.\mathrm{Fc} / \mathrm{Fc}^{+}\right) .{ }^{[14]}$ This likely reflects the different Lewis acidity of the boron and zinc centres together with a different degree of covalency in the metal-ligand bonding. Cyclic voltammetric characterisation indicates that both the singly-reduced radical anion and the doublyreduced dianionic states of $\mathbf{2} \mathbf{a}$ and $\mathbf{2 b}$ are synthetically accessible.

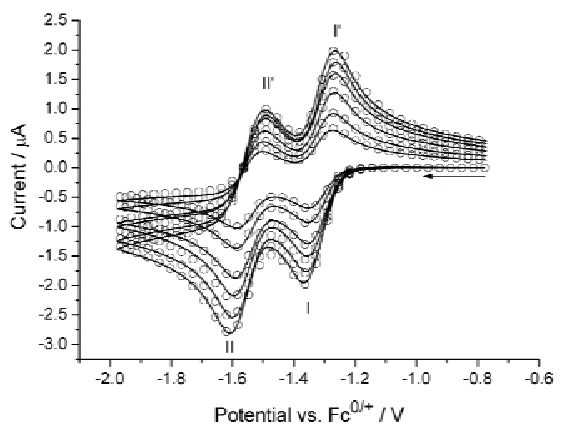

Figure 2. Cyclic voltammograms of a $2.5 \mathrm{mM}$ solution of $\mathbf{2 a}$ in THF $\left(0.1 \mathrm{M}\left[B u_{4} \mathrm{~N}\right]\left[\mathrm{B}\left(\mathrm{C}_{6} \mathrm{~F}_{5}\right)_{4}\right]\right)$ recorded at $100,200,400,600,800$, and $1000 \mathrm{mVs}^{-1}$. Solid lines = experimental data; open circles $=$ simulated data.

Table 1. Optimised electron transfer parameters determined from digital simulation of experimental voltammetry.

\begin{tabular}{|c|c|c|}
\hline $2 a$ & $E^{0}$ vs $\mathrm{Fc}^{0 /+} I \mathrm{~V}$ & $k^{0} / 10^{-2} \mathrm{cms}^{-1}$ \\
\hline System I/l' & $-1.31 \pm 0.01$ & $1.25 \pm 0.05$ \\
\hline System II/II' & $-1.55 \pm 0.01$ & $0.90 \pm 0.05$ \\
\hline \multicolumn{3}{|l|}{$2 b$} \\
\hline System I/I' & $-1.57 \pm 0.01$ & $1.30 \pm 0.05$ \\
\hline System II/II' & $-1.85 \pm 0.02$ & $0.75 \pm 0.05$ \\
\hline
\end{tabular}

In accordance with the $\mathrm{CV}$ data, the chemical reduction of neutral bis(formazanate) complexes $\mathbf{2 a}$ and $\mathbf{2 b}$ could be accomplished by treatment with 1.0 equiv of $\mathrm{Na}(\mathrm{Hg})$ in THF. The resulting radical species $\left[\mathrm{Na}(\mathrm{THF})_{3}\right]\left[(\mathrm{PhNNC}(\mathrm{R}) \mathrm{NNPh})_{2} \mathrm{Zn}\right](\mathrm{R}=p$ tolyl, $3 \mathbf{a} ; \mathrm{R}={ }^{t} \mathrm{Bu}, \mathbf{3 b}$ ) could be isolated as crystalline material by slow diffusion of hexane into the THF solution (Scheme 1). Compounds 3a and $\mathbf{3 b}$ are NMR silent but show broad EPR signals ( $g$-value $\sim 2$ ) both in THF and the solid state $(298$ and $77 \mathrm{~K}$ ) devoid of observable hyperfine coupling (Figure S3).

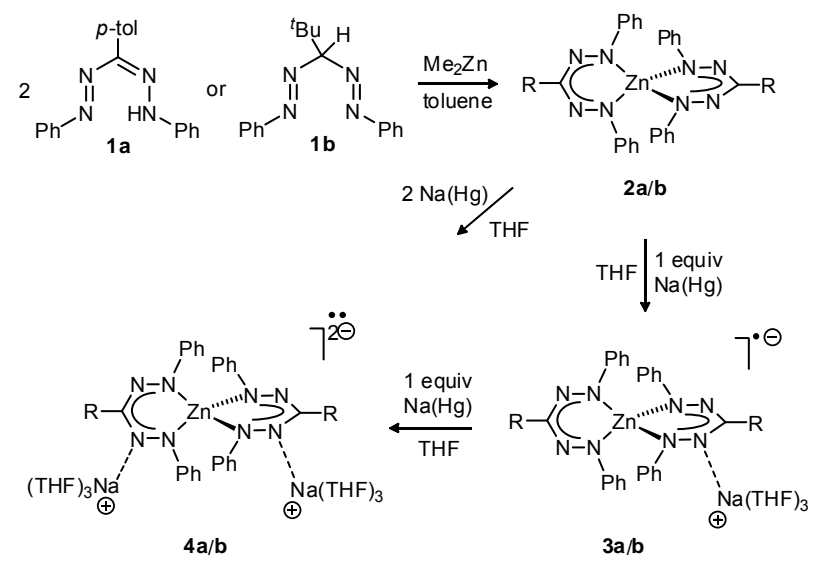

Scheme 1. Synthesis of neutral, monoanionic and dianionic bis(formazanate)zinc complexes

The crystallographically determined structures (Figures 3 and S1, pertinent bond distances in Table 2 and S2) show that the tetrahedral $\mathrm{L}_{2} \mathrm{Zn}^{-}$radical anion interacts with a $\mathrm{Na}(\mathrm{THF})_{3}{ }^{+}$cation through one (3a) or two (3b) nitrogen atoms of a formazanate ligand. ${ }^{[11]}$ A closer inspection of the metrical parameters within the formazanate backbone reveals that there are two distinctly different ligands in the $\mathrm{L}_{2} \mathrm{Zn}^{-}$fragment. One of the formazanates is very similar to those in the neutral precursors 2 (av. Zn-N: $2.014 \AA$; N-N: $1.304 \AA$ ), while the formazanate that binds the $\mathrm{Na}(\mathrm{THF})_{3}{ }^{+}$has shortened $\mathrm{Zn}-\mathrm{N}$ (av $1.957 \AA$ ) and elongated N-N bond lengths (av $1.363 \AA$ ). Thus, the $\mathrm{L}_{2} \mathrm{Zn}^{-}$anion is best described as a $\mathrm{Zn}^{2+}$ centre coordinated by a 'normal' monoanionic formazanate $\left(\mathrm{L}^{-}\right)$and a reduced dianionic ligand $\left(\mathrm{L}^{2-}\right)$. The $\mathrm{Zn}$-coordinated $\mathrm{L}^{2-}$ fragment can be considered an inorganic analogue of a verdazyl radical (Chart 1). ${ }^{[15]}$ The long N-N bonds in the $\mathrm{L}^{2-}$ fragment result from the unpaired electron occupying a molecular orbital (SOMO) which has $\pi^{*} \mathrm{~N}-\mathrm{N}$ antibonding character (vide infra). The observation of two distinct ligand redox states is likely related to electrostatic interactions with the cation, which localizes the additional negative charge. A similar situation is observed in related bis(ligand) complexes: in the case of neutral radical species $\left[\mathrm{PhB}\left(\mu-\mathrm{N}^{t} \mathrm{Bu}\right)_{2}\right]_{2} \mathrm{M}(\mathrm{M}=\mathrm{Al}, \mathrm{Ga})^{[16]}$ and $(\beta$ diketiminate $)_{2} \mathrm{Al}^{[17]}$ the unpaired electron is fully delocalized over the spirocyclic structure, while for the radical anions $[\mathrm{PhB}(\mu$ $\left.\left.\mathrm{N}^{t} \mathrm{Bu}\right)_{2}\right]_{2} \mathrm{M}^{-}(\mathrm{M}=\mathrm{Mg}, \mathrm{Zn})$ localized spin density is observed due to interaction with the cation. ${ }^{[18]}$

As suggested by the $\mathrm{CV}$ measurements, compounds $\mathbf{3}$ react with an additional equivalent of $\mathrm{Na}$ amalgam to give the dianionic complexes $\left[\mathrm{Na}(\mathrm{THF})_{3}\right]_{2}\left[(\mathrm{PhNNC}(\mathrm{R}) \mathrm{NNPh})_{2} \mathrm{Zn}\right](\mathrm{R}=p$-tolyl, 4a; $\mathrm{R}$ $\left.={ }^{t} \mathrm{Bu}, \mathbf{4 b}\right)$, of which $\mathbf{4 b}$ was crystallographically characterized (Figure 4, pertinent bond distances in Table 2) ${ }^{[11]}$ It contains two sodium cations that both interact with two $\mathrm{N}$-atoms of a different formazanate ligand. The presence of an additional electron in both ligands $\left(\mathrm{L}^{2-}\right)$ is evidenced by the similar bond lengths in $\mathbf{4 b}$, which are elongated in comparison to the neutral precursor $\mathbf{2 b}$ (Table 2). 


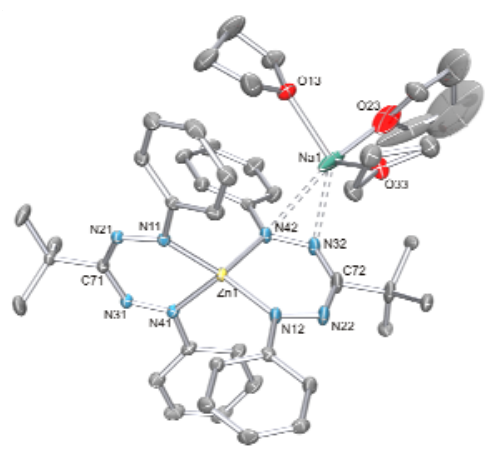

Figure 3. Molecular structure of $\mathbf{3 b}$ showing $50 \%$ probability ellipsoids. The hydrogen atoms are omitted for clarity.

Table 2. Selected Bond Distances in $\mathbf{2 b}, \mathbf{3 b}$ and $\mathbf{4 b}$.

\begin{tabular}{cccc}
\hline & $\mathbf{2 b}$ & $\mathbf{3 b}$ & $\mathbf{4 b}$ \\
\hline $\mathrm{Zn}(1)-\mathrm{N}(11)$ & $1.9824(17)$ & $1.9857(16)$ & $1.9793(14)$ \\
$\mathrm{Zn}(1)-\mathrm{N}(41)$ & $1.9822(18)$ & $2.0207(16)$ & $1.9839(14)$ \\
$\mathrm{Zn}(1)-\mathrm{N}(12)$ & $1.9902(17)$ & $1.9447(16)$ & $1.9696(14)$ \\
$\mathrm{Zn}(1)-\mathrm{N}(42)$ & $1.9769(18)$ & $1.9657(16)$ & $1.9952(15)$ \\
$\mathrm{N}(11)-\mathrm{N}(21)$ & $1.310(2)$ & $1.313(2)$ & $1.359(2)$ \\
$\mathrm{N}(31)-\mathrm{N}(41)$ & $1.307(2)$ & $1.295(2)$ & $1.376(2)$ \\
$\mathrm{N}(12)-\mathrm{N}(22)$ & $1.307(2)$ & $1.360(2)$ & $1.355(2)$ \\
$\mathrm{N}(32)-\mathrm{N}(42)$ & $1.309(2)$ & $1.370(2)$ & $1.378(2)$ \\
\hline
\end{tabular}

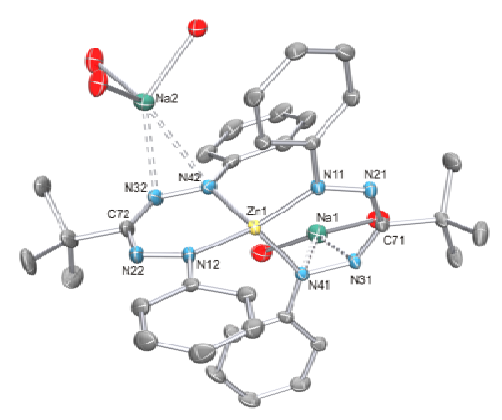

Figure 4. Molecular structure of $4 \mathrm{~b}$ showing $50 \%$ probability ellipsoids. The carbon atoms of the THF moieties and all hydrogen atoms are omitted for clarity.

EPR spectra of diradicals ${ }^{[19]} \mathbf{4 a}$ and $\mathbf{4 b}$ in frozen THF solution $(77 \mathrm{~K})$ are very similar and show features indicative of randomly oriented triplets $(\mathrm{g}=2.0028)$ with characteristic half-field $\left(\Delta \mathrm{m}_{\mathrm{s}}=2\right)$ signals (Figure 5). The zero-field splitting parameters $D=11.6 \times 10^{-}$ 3 and $11.5 \times 10^{-3} \mathrm{~cm}^{-1}$ from the EPR spectra for $\mathbf{4 a}$ and $\mathbf{4 b}$, respectively, are somewhat smaller than those in the neutral triplet diazabutadiene complex $\left[{ }^{t} \mathrm{Bu}_{2} \mathrm{DAB}\right]_{2} \mathrm{Zn}\left(23.1 \times 10^{-3} \mathrm{~cm}^{-1}\right),{ }^{[20]}$ and comparable to $D$-values found for purely organic phenylene-linked bis(radical) compounds (radical $=$ semiquinone $;{ }^{[21]}$ verdazyl), ${ }^{[2]}$ which range between ca. $4-10 \times 10^{-3} \mathrm{~cm}^{-1}$. It should be noted that although metal complexes with coordinated verdazyl radicals have been prepared, ${ }^{[23]}$ compounds 4 present the first examples of diradical 'metallaverdazyl' compounds.

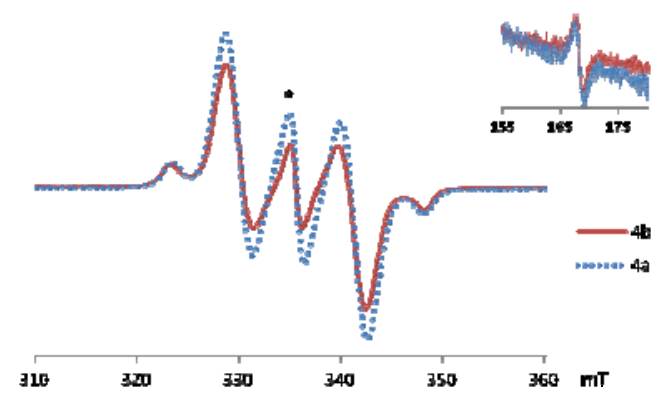

Figure 5. EPR spectra (frozen THF solution) of $\mathbf{4 a}$ and $\mathbf{4 b}$ (asterisk denotes a doublet impurity). Inset: half-field region.

UV-Vis spectroscopy of neutral, anionic and dianionic bis(formazanate) zinc compounds (Figure S2) provides additional evidence for ligand-based reduction and formation of verdazyl-type $\left(\mathrm{L}^{2-}\right)$ ligands. The neutral compounds $\mathbf{2 a}$ and $\mathbf{2 b}$ show single broad absorptions in the visible range at 578 and $536 \mathrm{~nm}$, respectively. The singly reduced compounds 3 have both formazanate $\left(\mathrm{L}^{-}\right)$and one-electron reduced, verdazyl-type $\left(\mathrm{L}^{2-}\right)$ ligands. As a consequence, they feature new absorption bands at longer (3a/3b: $769 / 755 \mathrm{~nm})$ and shorter wavelengths (3a/3b: $508 / 462 \mathrm{~nm})$ due to $\mathrm{L}^{2-}$; the position of these bands is similar to that observed in organic (Kuhn-type) triarylverdazyls. ${ }^{[24]}$ In addition, a weakened and bathochromically shifted absorption is observed which is attributed to the $\mathrm{L}^{-}$fragment in $\mathbf{3 a} / \mathbf{b}$. For compounds $\mathbf{4 a}$ and $\mathbf{4 b}$, the intensity of the low and high energy absorptions due to the $\mathrm{L}^{2-}$ fragment is increased relative to the singly reduced species 3 . The most prominent absorptions in the visible range are at 510/798 (4a) and 436/755 $\mathrm{nm}$ (4b) in agreement with the presence of only reduced formazanate (verdazyl-type) ligands.

DFT calculations were carried out to examine the electronic structure of the complexes described here. The crystallographically determined bond lengths and angles are reproduced accurately by (unrestricted) B3LYP/6-31G(d) calculations using Gaussian09 starting from the X-ray coordinates. However, geometry optimization of the 'free' radical anions 3 at the UB3LYP/6-31G(d) level of theory resulted in structures in which the SOMO is delocalized over both ligands. For example, in $\mathbf{3} \mathbf{a}_{\text {calc }}$ the diagnostic $\mathrm{N}-\mathrm{N}$ bond lengths are all equivalent at $\sim 1.322 \AA$, in between the short ( $\mathrm{L}^{-}$: av $1.304 \AA$ ) and long N-N bonds ( $\mathrm{L}^{2-}$ : av $1.361 \AA$ ) observed experimentally. When the countercation $\left[\mathrm{Na}(\mathrm{THF})_{3}\right]^{+}$that is present in the crystal structure determination is included in the computations, the unpaired electron is localized (see Figure 6 for $\left.3 \mathbf{a}_{\text {calc }}\right)$. This is in agreement with the experimental data and suggests that electrostatic effects are responsible for this localization. The calculated hyperfine interactions with the ${ }^{14} \mathrm{~N}$ nuclei are small in $3 \mathbf{a}_{\text {calc }}(<2.1 \mathrm{G})$, which likely accounts for the broad, featureless EPR signals observed experimentally. 

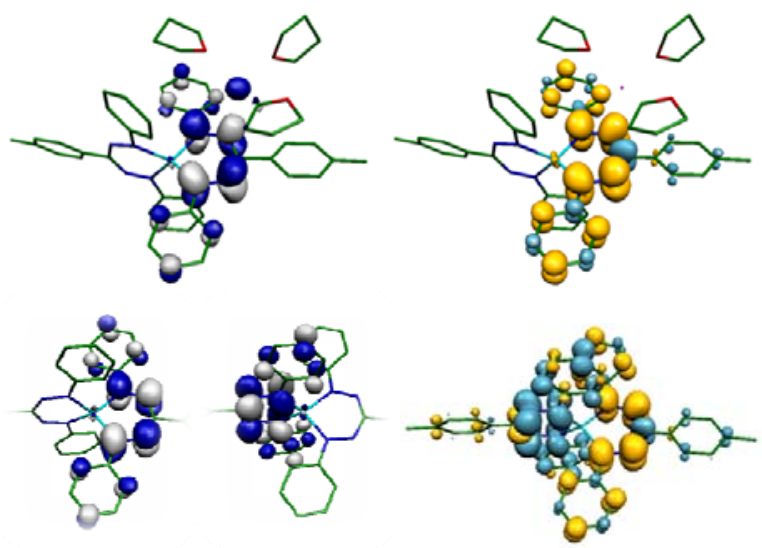

Figure 6. Top: SOMO (left) and spin density plot (right) for $\mathbf{3} \mathbf{a}_{\text {calc. }}$. Bottom: Two ligand-centered SOMOs for the BS $(1,1)$ solution (truncated structures, left) and spin density plot (right) for $\mathbf{4} \mathbf{a}_{\text {calc }}$.

For the diradicals 4 , geometry optimizations of the $\mathrm{L}_{2} \mathrm{Zn}^{-2}$ fragment in the absence of countercations converges at structures that have two (virtually) identical $\mathrm{L}^{-2}$ ligands with elongated N-N bond lengths of ca. $1.346 \AA$, which is somewhat shorter than those observed experimentally for $\mathbf{4 b}$ (av. $1.367 \AA$ ). Broken-symmetry DFT calculations ${ }^{[25]}$ show two ligand-based unpaired electron spins that are antiferromagnetically coupled $\left(J_{\text {calcd }}=-7.9 \mathrm{~cm}^{-1}\right)$ to give a singlet diradical ground state (Figure 6). The calculated spin density in diradical $\mathbf{4} \mathbf{a}_{\text {calc }}$ indicates that the unpaired electrons are located at the nitrogen atoms of the ligands, with some contribution of the aromatic substituents. To verify experimentally the ground state of 4a, preliminary EPR studies were carried out in the temperature range of $6-60 \mathrm{~K}$ (THF glass) to determine the temperature dependence of the EPR signal intensity (I). A plot of $I \times T$ vs. $T$ shows that $\mathrm{I} \times \mathrm{T}$ decreases upon lowering the temperature (Figure S4). This behaviour is indicative of a singlet diradical ground state, ${ }^{[19]}$ thus corroborating our computational results. Although singlet biradical species like $\mathbf{4}$ are rare, Roesky and co-workers recently reported a dicarbene zinc compound for which the singlet diradical was calculated to be lower in energy than the triplet by $\sim 4$ $\mathrm{kcal} / \mathrm{mol}^{[26]}$

In conclusion, we have shown that complexes with formazanate ligands give rise to reactivity that is not accessible with their $\beta$ diketiminate congeners. Bis(formazanate) zinc complexes engage in remarkably facile reductive chemistry to give isolable one- and twoelectron reduction products of $\mathrm{L}_{2} \mathrm{Zn}$, the stability of which results from the 'metallaverdazyl'-type structures obtained. The use of coordinated formazanates as reversible electron reservoir in (catalytic) reactions is currently under investigation in our laboratory.

\section{Experimental Section}

(PhNNC( $p$-tolyl)NNPh) $)_{2} \mathrm{Zn}$ (2a). A $1.2 \mathrm{M}$ solution of $\mathrm{Me}_{2} \mathrm{Zn}$ in toluene $(0.82 \mathrm{~mL}, 0.98 \mathrm{mmol})$ was added slowly to a suspension of $\operatorname{PhNNC}(p-$ tolyl)NNHPh $(620 \mathrm{mg}, 1.97 \mathrm{mmol})$ in $10 \mathrm{~mL}$ of toluene at room temperature. The mixture was stirred for $2 \mathrm{~h}$ after which the colour had changed to intense blue. The volatiles were removed in vacuo and the residue was subsequently extracted into a hot $3: 1$ hexane/toluene mixture. Slow cooling of the clear dark blue solution to $-30{ }^{\circ} \mathrm{C}$ for 2 days afforded $552 \mathrm{mg}$ dark violet crystals of (PhNNC( $p$-tolyl)NNPh) ${ }_{2} \mathrm{Zn}$.(toluene $)_{0.5}(0.75 \mathrm{mmol}, 76 \%) .{ }^{1} \mathrm{H}$ NMR $\left(200 \mathrm{MHz}, \mathrm{C}_{6} \mathrm{D}_{6}, 25^{\circ} \mathrm{C}\right) \delta 8.42(\mathrm{~d}, 2 \mathrm{H}, J=7.9$, p-tolyl $\mathrm{CH}), 7.70(\mathrm{~d}, 4 \mathrm{H}$,
$J=7.8$, Ph o- $\mathrm{H}$ ), 7.29 (d, 2H, $J=7.9$, p-tolyl CH), 6.81 (t, $4 \mathrm{H}, J=7.7$, $\mathrm{Ph} \mathrm{m}-\mathrm{H}$ ), 6.66 (t, 2H, J = 7.4, Ph p-H), 2.25 (s, 3H, p-tolyl $\mathrm{CH} 3) .{ }^{13} \mathrm{C}$ NMR (50.4 MHz, $\left.\mathrm{C}_{6} \mathrm{D}_{6}, 25{ }^{\circ} \mathrm{C}\right) \delta 152.8$ (Ph ipso-C), 144.0 (NCN), 137.6 ( $p$-tolyl ipso-C), 137.1 ( $p$-tolyl $\mathrm{CMe}$ ), 129.7 ( $\mathrm{Ph} m$-CH), 129.6 (p-tolyl $\mathrm{CH}$ ), $\sim 127.5$ (overlapped, $\mathrm{Ph} p$-CH), 126.4 (p-tolyl CH), 120.2 ( $\mathrm{Ph} \mathrm{o-CH}$ ), 21.2 ( $p$-tolyl $\mathrm{CH}_{3}$ ). Anal. Calcd for $\mathrm{C}_{43.5} \mathrm{H}_{38} \mathrm{~N}_{8} \mathrm{Zn}$ : C, 70.78; $H, 5.19 ; \mathrm{N}, 15.18$. Found: C, 70.74; H, 5.21; N, 15.13 .

$\left[\mathrm{Na}(\mathrm{THF})_{3}\right]^{+}\left[\left(\mathrm{PhNNC}(p \text {-tolyl)NNPh})_{2} \mathrm{Zn}\right]^{-}\right.$(3a). One leg of a doubleschlenk flask was charged with $2 \mathrm{a}(750 \mathrm{mg}, 1.02 \mathrm{mmol}), \mathrm{Na}(\mathrm{Hg})$ (2.447 wt\% Na, $1222 \mathrm{mg}, 1.30 \mathrm{mmol}$ ) and $15 \mathrm{~mL}$ of THF. The reaction mixture was stirred for overnight, filtered and reduced to half of the original volume. Slow diffusion of hexane $(15 \mathrm{~mL})$ into the THF solution precipitated $658 \mathrm{mg}$ of $\left[\mathrm{Na}(\mathrm{THF})_{3}\right]^{+}[(\mathrm{PhNNC}(p-$ tolyl)NNPh $)_{2} \mathrm{Zn}^{-}$as brown crystalline material $(0.707 \mathrm{mmol}, 69 \%)$. Anal. Calcd for $\mathrm{C}_{52} \mathrm{H}_{58} \mathrm{~N}_{8} \mathrm{NaO}_{3} \mathrm{Zn}: \mathrm{C}, 67.05 ; \mathrm{H}, 6.28 ; \mathrm{N}, 12.03$. Found: C, 66.84; H, 6.25; N, 11.90 .

$\left[\mathrm{Na}(\mathrm{THF})_{3}\right]_{2}{ }_{2}\left[\left(\mathrm{PhNNC}(\boldsymbol{p} \text {-tolyl)NNPh })_{2} \mathrm{Zn}\right]^{2-}\right.$ (4a). A mixture of solid $\mathbf{2 a}$ (50 mg, $0.068 \mathrm{mmol}$ ) and $149.5 \mathrm{mg} \mathrm{Na} / \mathrm{Hg}(2.447 \mathrm{wt} \%, 3.7 \mathrm{mg} \mathrm{Na}$, $0.159 \mathrm{mmol}$ ) was prepared. With stirring, $7 \mathrm{~mL}$ of THF was added at room temperature. After stirring the reaction mixture one week, $28 \mathrm{~mL}$ of pentane was added at room temperature to precipitate the product. The supernatant was decanted and the crystalline product washed with pentane to give $30.0 \mathrm{mg}$ of $\left[\mathrm{Na}(\mathrm{THF})_{3}\right]_{2}^{+}[(\mathrm{PhNNC}(p$ toyl)NNPh $\left.)_{2} \mathrm{Zn}\right]^{2-}$ as green crystalline material $(0.026 \mathrm{mmol}, 39 \%)$. Anal. Calcd for $\mathrm{C}_{64} \mathrm{H}_{82} \mathrm{~N}_{8} \mathrm{Na}_{2} \mathrm{O}_{6} \mathrm{Zn}$ : C, 65.55; $\mathrm{H}, 7.06 ; \mathrm{N}, 9.57$. Found: C, 65.53; H, 6.89; N, 9.87 .

Received: ((will be filled in by the editorial staff))

Published online on ((will be filled in by the editorial staff))

Keywords: radical ligands · zinc complexes · metallaverdazyl · formazanate $\cdot$ redox chemistry

[1] a) Chirik, P. J.; Wieghardt, K. Science 2010, 327, 794; b) Dzik, W. I.; van der Vlugt, J. I.; Reek, J. N. H.; de Bruin, B. Angew. Chem. Int. Ed. 2011, 50, 3356; c) Lyaskovskyy, V.; de Bruin, B. ACS Catal. 2012, 2, 270.

[2] Que, L.; Tolman, W. B. Nature 2008, 455, 333.

[3] Tsurugi, H.; Saito, T.; Tanahashi, H.; Arnold, J.; Mashima, K. J. Am. Chem. Soc. 2011, 133, 18673.

[4] a) Bouwkamp, M. W.; Bowman, A. C.; Lobkovsky, E.; Chirik, P. J. J. Am. Chem. Soc. 2006, 128, 13340; b) Bart, S. C.; Chlopek, K.; Bill, E.; Bouwkamp, M. W.; Lobkovsky, E.; Neese, F.; Wieghardt, K.; Chirik, P. J. J. Am. Chem. Soc. 2006, 128, 13901; c) Darmon, J. M.; Stieber, S. C. E.; Sylvester, K. T.; Fernández, I.; Lobkovsky, E.; Semproni, S. P.; Bill, E.; Wieghardt, K.; DeBeer, S.; Chirik, P. J. J. Am. Chem. Soc. 2012, 134, 17125; d) Tondreau, A. M.; Stieber, S. C. E.; Milsmann, C.; Lobkovsky, E.; Weyhermüller, T.; Semproni, S. P.; Chirik, P. J. Inorg. Chem. 2013, 52, 635.

[5] Bourget-Merle, L.; Lappert, M. F.; Severn, J. R. Chem. Rev. 2002, 102, 3031.

[6] a) Avent, A. G.; Hitchcock, P. B.; Khvostov, A. V.; Lappert, M. F.; Protchenko, A. V. Dalton Trans. 2004, 2272; b) Eisenstein, O.; Hitchcock, P. B.; Khvostov, A. V.; Lappert, M. F.; Maron, L.; Perrin, L.; Protchenko, A. V. J. Am. Chem. Soc. 2003, 125, 10790; c) Avent, A. G.; Khvostov, A. V.; Hitchcock, P. B.; Lappert, M. F. Chem. Commun. 2002, 1410.

[7] Khusniyarov, M. M.; Bill, E.; Weyhermüller, T.; Bothe, E.; Wieghardt, K. Angew. Chem. Int. Ed. 2011, 50, 1652.

[8] a) Basuli, F.; Kilgore, U. J.; Brown, D.; Huffman, J. C.; Mindiola, D. J. Organometallics 2004, 23, 6166; b) Hamaki, H.; Takeda, N.; Tokitoh, N. Organometallics 2006, 25, 2457; c) Bai, G.; Wei, P.; Stephan, D. W. Organometallics 2006, 25, 2649; d) Tomson, N. C.; Arnold, J.; Bergman, R. G. Organometallics 2010, 29, 5010.

[9] Nineham, A. W. Chem. Rev. 1955, 55, 355.

[10] a) Gilroy, J. B.; Patrick, B. O.; McDonald, R.; Hicks, R. G. Inorg. Chem. 2008, 47, 1287; b) Gilroy, J. B.; Ferguson, M. J.; McDonald, 
R.; Hicks, R. G. Inorg. Chim. Acta 2008, 361, 3388; c) Hong, S.; Hill, L. M. R.; Gupta, A. K.; Naab, B. D.; Gilroy, J. B.; Hicks, R. G.; Cramer, C. J.; Tolman, W. B. Inorg. Chem. 2009, 48, 4514.

[11] CCDC 972163-972167 contains the supplementary crystallographic data for this paper. These data can be obtained free of charge from The Cambridge Crystallographic Data Centre via www.ccdc.cam.ac.uk/data request/cif

[12] a) Cheng, M.; Moore, D. R.; Reczek, J. J.; Chamberlain, B. M.; Lobkovsky, E. B.; Coates, G. W. J. Am. Chem. Soc. 2001, 123, 8738; b) Tsai, Y.-C. Coord. Chem. Rev. 2012, 256, 722.

[13] Geiger, W. E.; Barrière, F. Acc. Chem. Res. 2010, 43, 1030.

[14] Gilroy, J. B.; Ferguson, M. J.; McDonald, R.; Patrick, B. O.; Hicks, R. G. Chem. Commun. 2007, 126.

[15] Hicks, R. G. Verdazyls and Related Radicals Containing the Hydrazyl [R2N-NR] Group; In Stable Radicals; John Wiley \& Sons, Ltd: 2010, p 245.

[16] Chivers, T.; Eisler, D. J.; Fedorchuk, C.; Schatte, G.; Tuononen, H. M.; Boere, R. T. Chem. Commun. 2005, 3930.

[17] Moilanen, J.; Borau-Garcia, J.; Roesler, R.; Tuononen, H. M. Chem. Commun. 2012, 48, 8949.

[18] Chivers, T.; Eisler, D. J.; Fedorchuk, C.; Schatte, G.; Tuononen, H. M.; Boeré, R. T. Inorg. Chem. 2006, 45, 2119.

[19] Abe, M. Chem. Rev. 2013.

[20] Gardiner, M. G.; Hanson, G. R.; Henderson, M. J.; Lee, F. C.; Raston, C. L. Inorg. Chem. 1994, 33, 2456.
[21] a) Shultz, D. A.; Boal, A. K.; Driscoll, D. J.; Kitchin, J. R.; Tew, G. N. J. Org. Chem. 1995, 60, 3578; b) Shultz, D. A.; Boal, A. K.; Farmer, G. T. J. Org. Chem. 1998, 63, 9462.

[22] a) Fico, R. M.; Hay, M. F.; Reese, S.; Hammond, S.; Lambert, E.; Fox, M. A. J. Org. Chem. 1999, 64, 9386; b) Gilroy, J. B.; McKinnon, S. D. J.; Kennepohl, P.; Zsombor, M. S.; Ferguson, M. J.; Thompson, L. K.; Hicks, R. G. J. Org. Chem. 2007, 72, 8062.

[23] a) Barclay, T. M.; Hicks, R. G.; Lemaire, M. T.; Thompson, L. K. Inorg. Chem. 2001, 40, 6521; b) Brook, D. J. R.; Yee, G. T.; Hundley, M.; Rogow, D.; Wong, J.; Van-Tu, K. Inorg. Chem. 2010, 49, 8573; c) Anderson, K. J.; Gilroy, J. B.; Patrick, B. O.; McDonald, R.; Ferguson, M. J.; Hicks, R. G. Inorg. Chim. Acta 2011, 374, 480.

[24] Kuhn, R.; Trischmann, H. Monatsh. . Chemie 1964, 95, 457.

[25] Neese, F. Coord. Chem. Rev. 2009, 253, 526.

[26] Singh, A. P.; Samuel, P. P.; Roesky, H. W.; Schwarzer, M. C.; Frenking, G.; Sidhu, N. S.; Dittrich, B. J. Am. Chem. Soc. 2013, 135, 7324. 
Entry for the Table of Contents (Please choose one layout)

\section{Redox Non-Innocent Ligands}

M.-C Chang, T. Dann, D. P. Day, M. Lutz, G. G. Wildgoose, E.

Otten*

Page - Page

The Formazanate Ligand as Electron

Reservoir: Bis(Formazanate) Zinc

Complexes Isolated in Three Redox

States
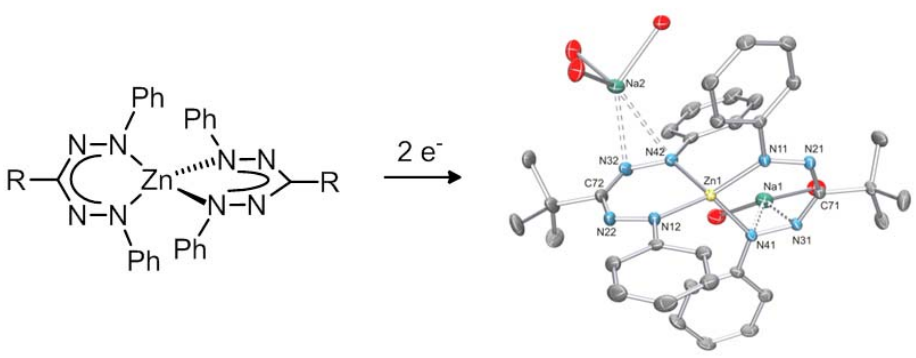

$\mathbf{N}$ is better than $\mathbf{C}$ : Bis(formazanate) zinc complexes show sequential and reversible redox-chemistry, in which the formazanate ligands are reduced to 'metalaverdazyl' radicals. The structural features of these ligands are very similar to well-known $\beta$-diketiminates, but the nitrogen-rich (NNCNN) backbone of formazanates opens the door to redox-chemistry not easily accessible otherwise. 